\title{
A case of giant, isolated renal angiomyolipoma in an elderly female
}

\author{
W A S De Silva ${ }^{1}$, N S Wijekoon ${ }^{1}$, K D C Quintus ${ }^{1}$, S K Rajasinghe ${ }^{1}$, D M I Dissanayaka ${ }^{1}$
}

\section{Introduction}

Renal angiomyolipoma is an uncommon, benign neoplasm. Although it is seen in association with tuberous sclerosis, the majority (80\%) occur in isolation. Isolated tumours predominantly occur in middle aged females, and mostly arise from the right kidney [1]. Larger tumours are known to be associated with a significant risk of rupture (traumatic or spontaneous) resulting in haemorrhagic complications [2]. We report a case of a giant, uncomplicated, isolated angiomyolipoma arising from the left kidney in an elderly female.

\section{Case report}

A 76-year old female presented with a history of progressive abdominal distention of 4 months duration without any other symptoms. She had no history of tuberous sclerosis or other medical illness. Examination showed generalised abdominal distention with a large, ballotable mass in the left flank. Ultrasonography and CT suggested a large left renal angiomyolipoma with remnants of left kidney (Figure1). She underwent a left radical nephrectomy and a tumour weighing $4.5 \mathrm{~kg}$ was excised. Histology confirmed the diagnosis of renal angiomyolipoma.

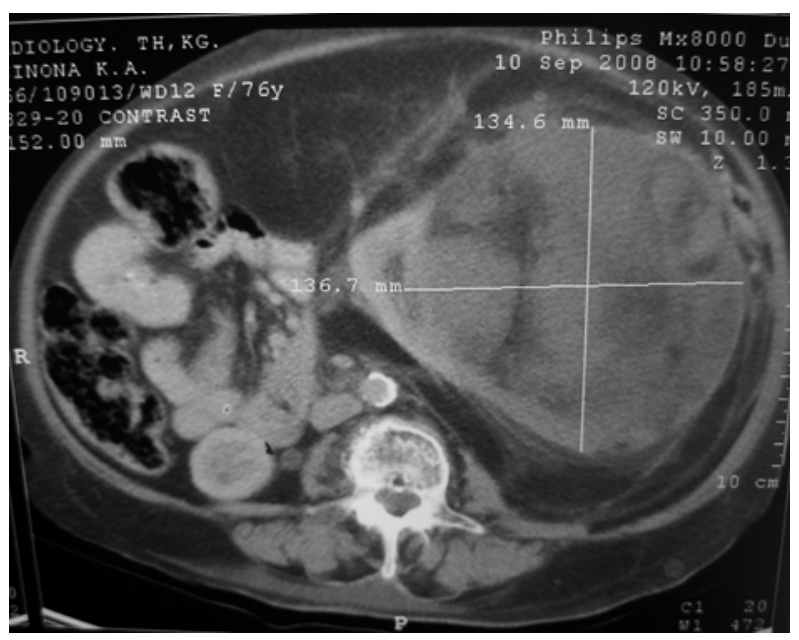

\section{Discussion}

Angiomyolipomas are composed of 3 tissue elements: mature adipose tissue, smooth muscle cells, and thickwalled blood vessels. These can develop in 2 forms. The isolated form which is the commonest $(80 \%)$, occurs sporadically, and the remaining $20 \%$ are associated with tuberous sclerosis. The isolated type is often solitary; presents at a mean age of 43 years; is commoner in women and $80 \%$ arise from the right kidney [2]. In this case, the patient was a 76-year old female where the tumour involved the left kidney.

The size can vary from a few millimeters to being larger than $20 \mathrm{~cm}$. The majority (60\%) are asymptomatic. However, about $82 \%$ to $94 \%$ of angiomyolipomas equal to or greater than $4 \mathrm{~cm}$ in diameter are symptomatic, and the main presenting symptoms are related to intratumoural or retroperitoneal haemorrhage [3]. Typical angiomyolipomas can be diagnosed without histological confirmation by a combination of ultrasound and CT in up to 95\% of cases. On ultrasonography they cannot be confidently differentiated from renal cell carcinoma. However, the characteristic detection of fat within the lesion by CT is diagnostic [4].

Figure 1. CT images showing the angiomyolipoma.

${ }^{1}$ Department of Urology, Teaching Hospital, Kurunegala, Sri Lanka.

Correspondence: NSW, e-mail <naveenwijekoon@yahoo.com.au>. Received 20 January and revised version accepted 21 July 2010. Competing interests: none declared. 
The management depends on factors such as tumour size, risk of haemorrhage, and whether the lesion is sporadic or associated with tuberous sclerosis. Symptomatic, large tumours require surgical intervention. Smaller $(<4 \mathrm{~cm})$, asymptomatic tumours can be managed conservatively with close monitoring using newer imaging techniques (CT, MRI). Radical nephrectomy should be the procedure of choice if there is any suspicion of malignancy [5].

\section{References}

1. Rakowski SK, Winterkorn EB, Paul E, Steele DJ, Halpern EF, Thiele EA. Renal manifestations of tuberous sclerosis complex: incidence, prognosis, and predictive factors. Kidney International 2006; 70: 1777-82.
2. Nelson CP, Sanda MG. Contemporary diagnosis and management of renal angiomyolipoma. Journal of Urology 2002; 168: 1315-25.

3. Limaiem F, Mekni A, Chelly I. Renal epithelioid angiomyolipoma: a case report and literature review. Pathologica 2008; 100: 31-5.

4. Prasad SR, Surabhi VR, Menias CO, Raut AA, Chintapalli KN. Benign renal neoplasms in adults: cross-sectional imaging findings. American Journal of Roentgenology 2008; 190:158-64.

5. Wong K, Waters CM, Hershman MJ, Kaisary AV, Horner J. Angiomyolipoma of the kidney: a clinical enigma in diagnosis and management. Annals of Royal College of Surgery of England 1992; 74: 144-8. 